\title{
ARCHITECTURE AS A DEVICE: THE DESIGN OF WASTE RECYCLING COLLECTION CENTRES
}

\author{
Maria Luna Nobile * \\ DiARC Department of Architecture, University of Napoli Federico II, via Toledo 402, 80123 Napoli, Italy
}
Article Info:
Received:
17 January 2018
Revised:
16 May 2018
Accepted:
19 June 2018
Available online:
30 June 2018
Keywords:
Recycle centres
Architecture
Device
Integration
Contamination
Upcycle

\begin{abstract}
Thinking about the architectural project as a broader process first requires reflecting on the role of architecture in urban transformation. The current debate's main actors are theoreticians and architects, demonstrating that it is possible to direct one's gaze to a new way of conceiving architecture as a device. The proposed topic is related to research conducted on the architecture and design of public spaces for waste recycling collection centres in the Department of Architecture of the University Federico II in Naples, Italy. The main idea is to conceive waste recycling collection centres not only for their service function but for public spaces in the city. The waste collection centres can have new associated functions, such as laboratories, markets, exhibition areas and rooms for educational activities. According to the guidelines of the Campania Region, a recycling collection centre is an area located in the city, and the number of centres is proportional to the number of citizens. According to these guidelines, the project wants to demonstrate that it is possible to avoid the NIMBY (Not In My Backyard) effect and to integrate this inconvenient function within the city centre, connecting these centres with other activities intended for community use that can be integrated with the size and the function of the recycling collection centre. This functional contamination does not mask an inconvenient function but increases the social value of these places. The case studies for designing waste recycling collection centres were developed according to the guidelines of this research and are described in this article.
\end{abstract}

\section{INTRODUCTION}

\subsection{Architecture and Waste}

As cities are rapidly expanding and their populations increasing, the topic of waste and energy is becoming urgent in terms of defining new innovative and sustainable solutions to manage and reduce the amount of waste, particularly through improving citizens' education and habits. To fight the problems connected with global climate change and increasing pollution, the proposed research focuses on one aspect of this problem: to define the role of the architecture and design discipline in waste management as one of the crucial aspects in finding solutions to improve the relation between city users and the city's main infrastructure.

In recent years, the relationship between architecture and waste collection centres has emerged from the partnership between architecture and industry that achieved prominence during the 20th century.

Many architects, such as Walter Gropius, Eero Saarinen and Norman Foster, have developed important buildings that transformed an 'ugly' space into an opportunity, mak- ing factories more human (Kara, 2017). The idea that architecture can add value in the design of waste management centres, particularly those in urban cities, started with my 2004 research in Napoli during the last phase of my studies in architecture at the Department of Architecture in the University Federico II of Naples, and in 2016, the idea became the subject for my post-doctoral research on the design of waste recycling collection centres.

Considering everyone's daily lives depend upon industrial and infrastructure facilities and the increasing problems connected with urban design in the Anthropocene era, architects must consider the relation between the community (the users of architecture) and planning and design strategies.

\subsection{Architectural Design as an Integration Tool for Different Subjects}

Citizens, the economy and the environment are essential elements in an urban project. Architecture must be regarded as an instrument of convergence for the implementation of social, economic and environmental practices, in which the architect's role cannot be separated from the 
social and economic aspects.

Today, planning processes are increasingly linked to, and sometimes dependent upon, economic and political factors, placing the morphological and social aspects in the background. Cities are complex scenarios where it is increasingly difficult to distinguish responsibilities and roles in the management and development of urban regeneration strategies.

From 2004 to 2016, the proposed research had several occasions to reflect on the relation between architecture and community. In 2010, the International Congress of EURAU '10 (European Symposium on Architecture and Urban Research), organised by the Department of Architecture of the University of Naples Federico II, focused on the relationship between the quality in architecture (venustas) and democracy. The Congress, which completed its work in June 2010, wanted to propose a way of building a 'community', contemplating state-of-the-art methods in the European areas of education, research and architectural culture and providing inspiration for the National Research PRIN, which in subsequent years (2012-2013) produced reflections on the role of research in architecture and its 'utility' (PRIN "Research projects of national interest", funded by the the Italian Ministry of Education: "Architettura-mercato-democrazia: come si valuta la "venustas" dell'architettura?").

The 12th Architecture Biennale of 2010, 'People Meets in Architecture', dealt with the same theme and focused on the idea that architecture can be the mirror of collective awareness in a rapidly changing society. Imagining the city of the future means assuming as a fundamental premise that:

Architecture is an art that helps building the res publica, the spaces in which we live and organize our civilization in which we recognize, that we own without being owners, but that is part of our being men and society. People meet in architecture also means that we become people in architecture; It is in the res publica that man crowns his own effort to build society (Sejima 2010).

The recent 2016 Architecture Biennale, 'Reporting from the Front', underscored and confirmed what was said in the 2010 edition, and it focused on the integration of architecture and other disciplines. The architect's role was deepened in all its different aspects, and architecture worked together with other disciplines in planning and managing the territories, in which the inhabitants and citizens play a central role (and mostly focused on the connection between architecture and community), with respect to the logic architecture had used to conduct its studies during the previous 50 years (Aravena 2016).

Today, an architectural project represents a tool for the convergence of disciplines, where architecture, along with other skills, evolve a city, reorganising the activities and involving citizens in the construction of a society that strives for the proper utilisation of resources and for achieving the common good.

\subsection{The Architect's Role in the Climate Change Era}

The past 50 years have shown that rapid urban growth, in some cases worrying and uninterrupted, has contributed to drastically reducing the resources available to humans. This uncontrolled growth has led to a series of problems that have contributed to climate change, and these problems will only worsen without a constant and intense reduction in human consumption. Climate change has raised public awareness, changing how one thinks of a city. Now, a city must be conceived as a place of experimentation, where citizens, politicians, investors, administrators and technicians, working together, can help in improving the living conditions of the inhabitants and in achieving a sustainable future.

Climate change studies have considered architecture one of the most important disciplines. Such studies are desperately trying to intervene through the introduction of legal protocols, international agreements and policy strategies, putting the theme of global consumption reduction at the centre of world attention; however, there is no going back, and society must adapt its knowledge to a new way of interpreting current climate issues (Figure 1).

The Urban Age conference, organised by the London School of Economics and Alfred Herrhausen Gesellschaft during the 14th Architecture Biennial of 2016, featured the major players currently involved in the city development debate. The conference was a way to consider some of the questions that concern the modern city (conceived as a set of citizens living in a given environment) both in the present and in the near future. Joan Clos, Director of Habitat III and UN Undersecretary, participated in the conference's concluding session, which anticipated and proposed guidelines for formulating a New Urban Agenda that will help shape the 21st century (Clos, 2016).

The Urban Age conference in Venice dealt with six different themes that includedthe following questions:

1. What are the economic and political forces that shape the urban society?

2. Impact of project design on city expansion: is it possible to control urban growth through the planning process?

3. Adapting and social integration in the city: how can the spaces promote interactions between different cultures?

4. What is the role of architecture? How can architecture respond to social challenges and daily environmental problems? What are the design limits in facing the human condition and nature?

Starting from these considerations, the research focused on the architect's role in managing and organising the city and stressed one of the conference's main interests: the cycle of waste and the management of spaces designed for the collection of the materials to be recycled, or waste recycling collection centres.

Thinking about the architectural project as a broader process first requires a different way of perceiving architecture's role in urban transformation. The current debate's main actors are theoreticians and architects, demonstrating that it is possible to direct one's gaze to a new way of conceiving architecture as a device (MVRDV, 2005). Archi- 

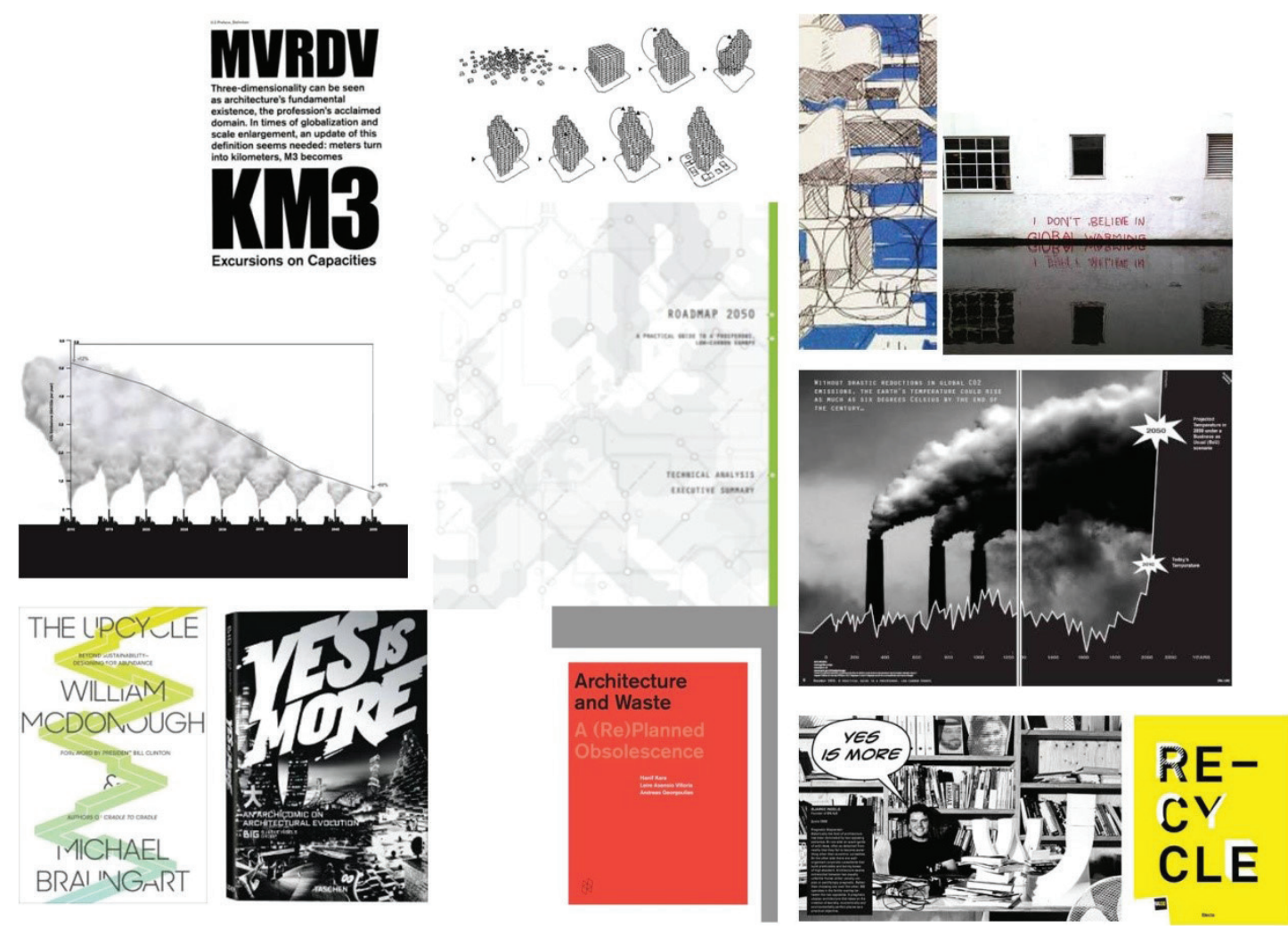

FIGURE 1: Studies and researches about climate changes, waste, ecology and architecture (graphic by M.L.Nobile).

tecture becomes not only the design of a new space but a device, the process that drives the action during different phases.

The research presented in this paper focuses on the project's role in the use of public space and, thus, the project's role in its overall development, from the idea to the result, as a line tool applicable in different situations.

\section{THE DESIGN OF WASTE RECYCLING COL- LECTION CENTRES}

\subsection{The Architectural Project as a Tool for Collective Practices in the Design of Public 'Infrastructures'}

The relationship between 'usefulness' and 'quality' in architecture is clearly evident in some large waste disposal projects (recycling plants and large waste incineration plants), not only for the urban value and the architectural interest of the object itself but particularly for the social and anthropological urban value that this way of 'making architecture' represents for the development of modern cities. Architecture becomes the instrument for communicating to citizens for 'didactic' purposes, teaching it is possible to treat 'waste'.

Usually, the character of such waste management plants is ugly and unwelcoming. Being only functional places, like factories, they are conceived as disconnected from the public, both from the social and visual points of view. In the last year, a Harvard University research entitled 'Architecture and Waste' (Kara, 2017) highlighted several examples and case studies of waste-to-energy plants that integrate public functions to engage communities beyond their core function. This research demonstrated how architecture can help in creating new opportunities. Recent experiments in hybrid architecture integrated recreational activities into the heart of previously uninhabited and largely forbidden public areas. The sky slope of the waste incinerator in Copenhagen, designed by BIG, and the educational centres in Brooklyn recycling facilities are just a few examples of architecture's contribution to the design of these infrastructures: 'These facilities spotlight how architects can create value in otherwise dull and alienated industrial environments, infusing them with a sense of community and purpose. Beyond their aesthetic qualities, these buildings also exceed established standards of environmental performance' (Kara, 2015).

An example of this kind of infrastructure is the Naka Waste Incineration Plant of Hiroshima, which the Japanese call a 'fusion design', marking the collaboration among architects, civil engineers, landscape designers, industrial hygienists and other figures. The Naka plant represents not only one of the most interesting and innovative infrastructures in Japan but also a structure that is capable of connecting the city with the sea (Figure 2).

The aim of the architect, Yoshio Tanigushi, was to bring the visitors (more than 200.000 a year) directly to the seaside, crossing the central corridor, the 'Ecorium', that has a double function: first, to enter and show what happens inside the plant and, second, to cross the enormous terrace that overlooks the sea. The architecture, conceived as a device and as a public space that belongs to the city, 

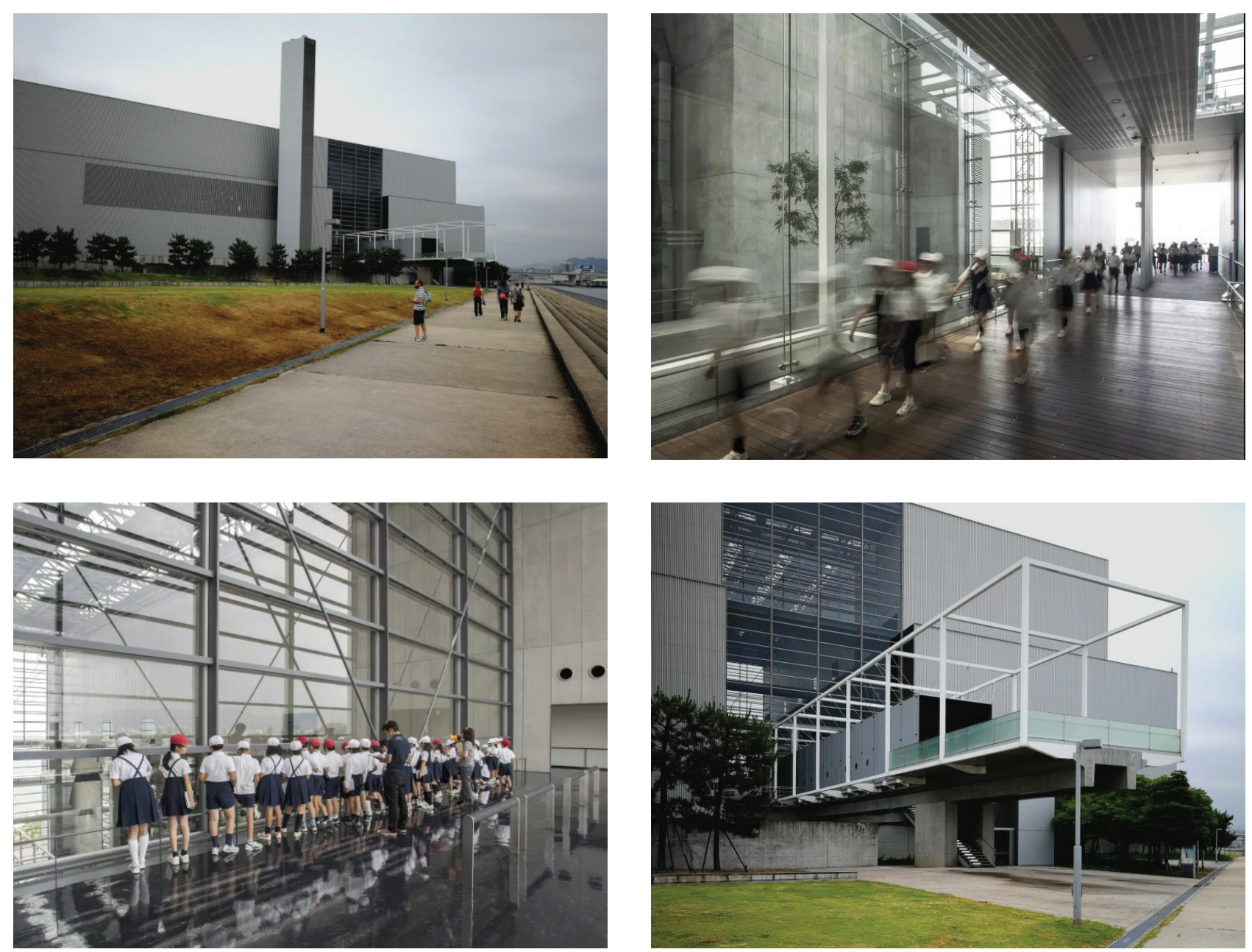

FIGURE 2: The Naka Waste Incineration Plant of Hiroshima, architecture as a device (on the top-left and bottom-right ph. M.L.Nobile, on the top-right and bottom-left ph. A.Guarino)

improves the communication and the didactic aim. The visitors' path, which represents an extension of Yoshijima Street, ends outdoors on this platform cantilevered over a newly incorporated public park, providing a wonderful view of the harbour.

Therefore, waste-to-energy plants are one of the most interesting and challenging examples of the integration between architecture and other disciplines.

\subsection{Research on the Design of Public Spaces for Waste Recycling Collection Centres}

The more general topic of the interaction between architecture and waste plants (incinerator and recycling plants) is the starting point of the research presented in this paper.

The research has been developed in the Department of Architecture of the University Federico II in Naples and focuses on a specific topic: how the architecture and design of public space has a role in the planning of waste recycling collection centres (Amirante, 2006). The main idea is to conceive theseplaces not only as services but as facilities with new functions, such as laboratories, markets, exhibition areas and rooms for educational activities.

This research is based on the knowledge that these places work well only if they are inside the city and near the places where citizens live. Thus, the value of waste recycling collection centres is not only in the quality of each element but in the form of the place and in the relationship that each centre builds with others and with the land. The research investigates the possibility of considering waste collection centres not as a 'problem to solve' but as 'an opportunity to play'.

In Italy, waste is managed at a municipal level in accordance with national legislation, and the management practices differ widely from area to area, as the general law is applied at local levels through detailed regional guidelines. In the 14 years since the garbage crisis, municipalities have been increasing access to recycling services and domestic collections.

According to the Campania Region's guidelines, a waste recycling collection centre is an area that is located in the city centre, and the number of collecting centres in the city is proportional to the number of citizens. These guidelines fix the size of the centre and the general requirements: a space for collecting the different materials (plastic, glass, paper, textiles, WEEE, oil), a ramp, a small cabin for the guardian and an enclosure. In the guidelines, the quality of those spaces is not mentioned. If thinking about waste 
recycling collection centres as a local service, one cannot imagine them as impenetrable enclosures; their locations must be chosen not only for economic and functional principles but for the possibility of demonstrating that it is possible to avoid the NIMBY effect and to integrate this inconvenient function in the city centre, connecting these facilities with other activities intended for community use.

This functional contamination does not mask an inconvenient function but shows the centre's social value is greater than it may appear. The integration of public functions and service functions represents how the 'standard collecting centre' specifies its own characteristics in relation to each place. The 'associated function' started with the place's position in the centre of the city, i.e. from its 'urban rule', and this is used to train citizens to recycle. Thus, reflecting on each element of the centre's architecture is essential to show their representative components, ranging from the semantic to the iconic, from the virtual to the possible, from the communication to the information. Urban design has converted waste recycling collection centres, as an architectural theme, integrating them with the context and mending the split in the city's fabric, representing a new function centre that contributes to the citizens' knowledge and education.

\section{APPLICATION AND PROJECTS}

\subsection{The Research: The Design of the Waste Collec- tion Centres in Nocera Inferiore and in the Metropol- itan area of Naples 2004/2016}

The research has been the occasion to reflect on architecture's useful dimension, particularly regarding the design of waste collection areas. For many years, numerous architects have confronted the theme of designing large facilities for the collection and disposal of solid waste (mentioned above); however, few current researches are studying the areas closer to citizens, places within the urban centres, which are destined for the separate collection of waste to be recycled(plastic, glass, paper, textiles, WEEE, oil). Public administrations throughout Europe have implemented several strategies and have introduced regulations since the early 2000s to favour the gradual reduction of urban solid waste production. The Campania Region published guidelines for the drafting of eco-design projects in Law Order No. 11 on September 13, 2000, when the waste management topic became an emergency.

This research consists of two steps. The first step was the agreement in 2004/2006 between the Department of Architecture of the University of Naples and the Municipality of Nocera Inferiore, a city of 40.000 inhabitants in the
Campania Region, south of Italy.

The research was developed with 25 students from the final-year course in Architecture, who started to design several projects in different parts of the city. The aim was to demonstrate how to design a waste collection centre as a public space, integrating the service function with a collateral function (educational laboratories, public areas, children's playgrounds, gardens). In 2006, the final projects of the master's degree in Architecture students delved deeper into the topic. I developed my Final Project in 2006 on the topic of Waste Facility Infrastructures as an Architectural topic: A design project for a Waste collecting centre in Nocera Inferiore (Tutor prof. Roberta Amirante, co-tutor Paola Scala, Orfina Fatigato, Department of Architecture University Federico II of Napoli).

This virtuous process produced a public tender for the design of a waste recycling collection centre: in 2009, the Municipality of Nocera Inferiore decided to build a waste recycling collection centre following the guidelines of the Campania Region but integrating those guidelines with the results of the research held in collaboration with the University of Naples. The design team (coordinated by Prof. Architect Sergio Pone) conceived this infrastructure as a 'hybrid' architecture, a place that could be used as a public space for events and concerts, a public square and a community area (Figure 3).

Every year, this structure hosts a festival called the 'Campania Eco Festival', and the event started with the building, which is one of the most interesting examples in Italy of a waste recycling collection centre that hosts a different 'hybrid' function, as conceived in its architectural design concept. The waste recycling collection centre in Nocera Inferiore is a public space that at different times of the year becomes a meeting place where the typical functions of living together blend into functional use, and this helps raise awareness and educate the citizens on the topic of waste management. During the day, the facility serves as a normal collection centre. The different setting and the disposal of the waste containers makes it possible to use the ramp as a stage, and the shelter hosts the area for the public audience.

The research's second phase, designing the waste collection centres in the metropolitan area of Naples 2016/2017, is currently ongoing. The research project, funded by the Campania Region, started in 2016 and considers the possibility of creating a network of waste recycling collection centres in the metropolitan area of Naples using the regional highway (research group: R. Amirante coordinator, P. Miano, C. Piscopo, S. Pone, P. Scala, M. Rus-

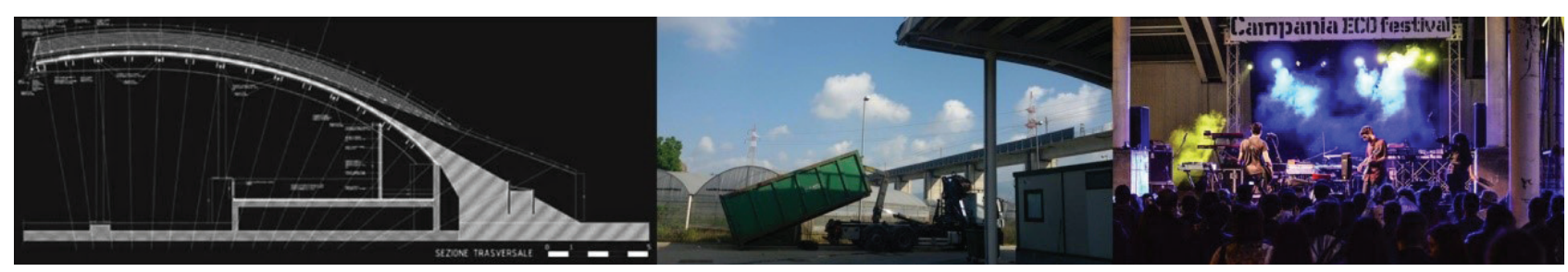

FIGURE 3: Waste recycling collection centre in Nocera Inferiore (drawing by CMMKM, ph. Campania Eco Festival). 

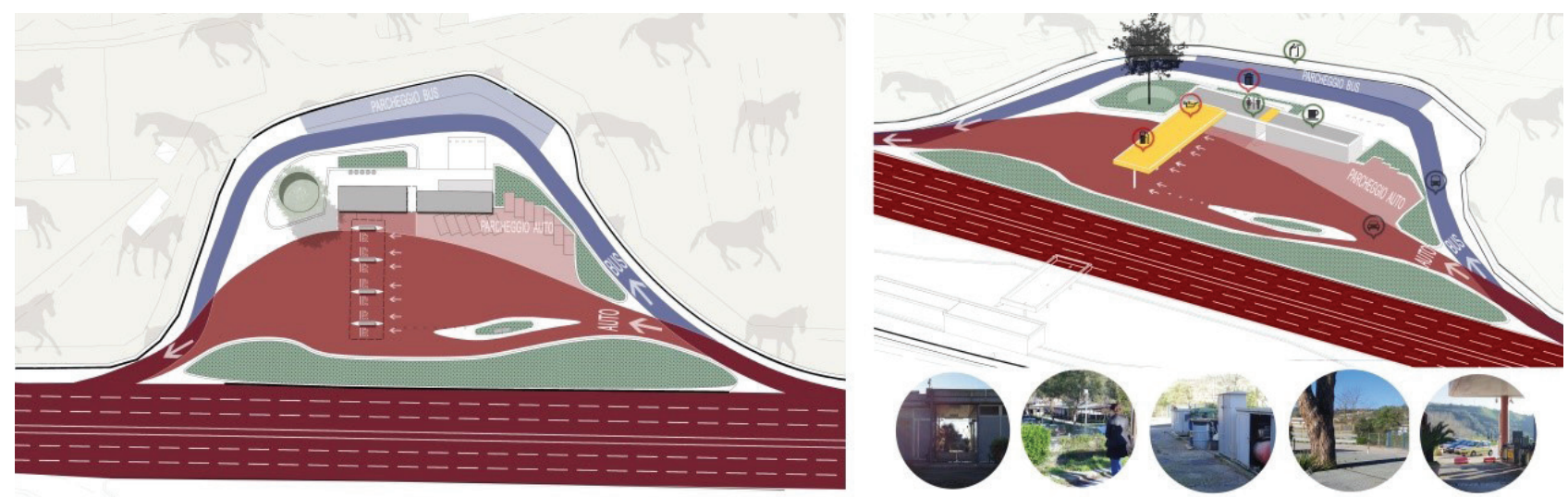

FIGURE 4: The reuse of regional highway's service areas in metropolitan Naples (drawing by Alessandra Acampora, Veronica De Falco, Maria Luna Nobile, Bianca Parenti).

so, A. Acampora, M. Castigliano, V. De Falco, M. L. Nobile, B. Parenti - Department of Architecture, University Federico II of Naples) - Figure 4.

Based on the considerations highlighted in the first part of this paper, and considering that during the 10 years (from building the Ecological centre in Nocera Inferiore in 2007 to the approval of the research project in 2017) the situation in the Campania Region has been changing-Campania's municipalities are currently equipped with waste recycling collection centres-the research has considered the current legislation and the actions provided for in the revised Programming Addresses of the Urban Waste Management Plan in the Campania Region through the addition of the C.I.R.O, Integrated Centres for the Optimal Reuse of Durable Goods, particularly the reuse of WEEE - Wood - Metal - Bulk - Textile.

This consideration was used to initiate a discussion on the hypothesis of designing a collection space for the modification of such types of 'waste', giving them a new life. This project hypothesis is not only architectural but initiates a virtuous process that blends the logic of space organisation into the management and sustainability of the proposed actions. The logic of 'utility' becomes the main theme for reconsidering 'waste' spaces, urban areas and the architectural objects of the regional highway's service areas in metropolitan Naples (disused shelter, parking areas, etc.) - Figure 5.

Considering the main aim of the research project, this article focused on integrating different functions into the design of waste management collection centres, highlighting the 'upcycling' process. Introduced in the research of architect William McDonough and chemist Michael Braungart, upcycling is the specific moment that defines the end of one cycle and the starting point of a new cycle.

The term upcycling was coined in Cradle to Cradle, a book on ecologically intelligent design. In its simplest terms, upcycling is the practice of taking something that is disposable and transforming it into something of greater use and value. Upcycling repurposes materials that are not easily recycled into something useful or artistic. Therefore, the action is intended to return a new quality, breathing new life into discarded materials.

The research investigates the possibility of considering waste collection centres not as a 'problem to solve' but as 'an opportunity to play'. Designing the waste management centres on the highway in Naples was an opportunity to
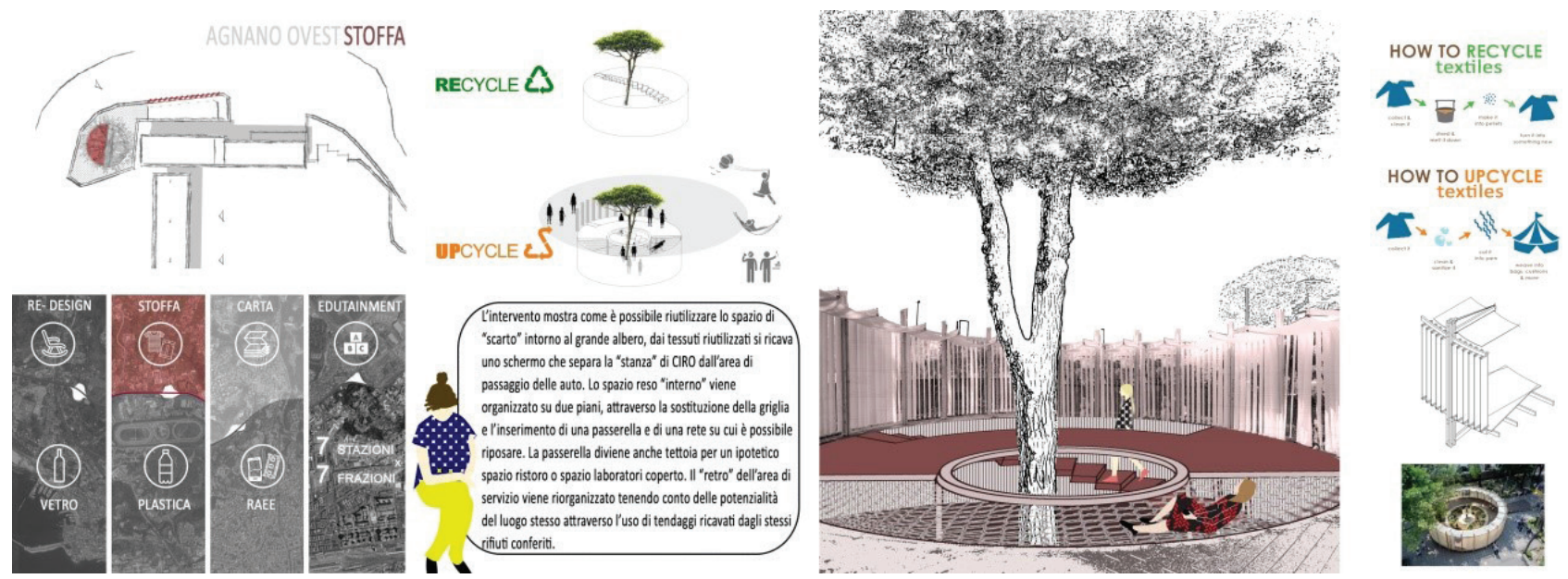

FIGURE 5: Upcycling the regional highway's service areas in Naples: the Integrated Centres for the Optimal Reuse of Durable Goods (drawing by Alessandra Acampora, Veronica De Falco, Maria Luna Nobile, Bianca Parenti). 
experiment with the upcycle concept in the abandoned or 'wasted' regions that are included in the highway's service areas. This concept that is still a work in progress could be improved and applied to other similar areas.

\section{REFERENCES}

Aa. Vv., (2011) Re-cycle, Electa, Milano.

Ábalos, I. \& Herreros, J. (1999) "Ecomonumentalidad=Ecomonumentality" in Quaderns. No. 224, Destellos = Flashes. Barcelona.

Ábalos I. \& Herreros J., (2000) Reciclando/Recycling Madrid. Actar Ed. Barcelona.

Amirante R., (2006) (a cura di), Le isole ecologiche, un tema di architettura, Editoriale Franco Alfano, Nocera Inferiore.

Amirante R., Scala P., Piscopo C. (2016). La bellezza per il rospo / Beauty according to the toad, Clean, Napoli.

Avermaete, T., Hooimeijer F., Schrijver L. (2006). Urban Formations and Collective Spaces. Oase. Architectural Journal 71.

BIG, (2011). Yes is more, Taschen, Khöln.

Brown H., (2017) Infrastructural Ecologies: Alternative Development Models for Emerging Economies, MIT Press.

Brown H., (2014) Next Generation Infrastructure: Principles for Post-Industrial Public Works.

Corbellini G., (2000) Grande e Veloce. Strumenti compositivi nei contesti contemporanei, Officina, Roma.

La Cecla, F., (1993.) Mente Locale, Eleuthèra.
Kara H., Asensio Villoria L., Georgoulias A., (2017) Architecture and Waste, a (re) planned obsolescence, Actar Publishers, Harvard University Graduate School of Design.

Koolhaas, R., (1995). S,M,L,XL, The Monacelli Press, 1995.

Marini, S., Santangelo, V. (2013). Recycland (a cura di), ARACNE editrice S.r.l., Roma.

McDonough, W., Braungart, M., (2003). Dalla culla alla culla. Come conciliare tutela dell'ambiente, equità sociale e sviluppo, Torino, Blu Edizioni.

MVRDV, (2005). KM3 Excursions on capacities, ACTAR, Barcelona.

Sejima K. (2010). La Biennale di Venezia. 12a Mostra Internazionale di Architettura. People meet in architecture. Catalogo della mostra, Marzilio Editore, Venezia.

Viale G., (2000) La civiltà dei rifiuti e i rifiuti della civiltà, Feltrinelli, Milano Viale G., (2010) La civiltà del riuso, Edizioni Laterza, Bari.

\section{WEB REFERENCES:}

1. http://www.harvarddesignmagazine.org/issues/40/the-missing-link-architecture-and-waste-management

2. https://urbanage.Isecities.net/conferences/shaping-cities-venice-2016

3. http://www.dezeen.com/2016/01/13/alejandro-aravena-interview-pritzker-prize-laureate-2016-social-incremental-housing-chilean-architect/

4. http://www.metropolismag.com/uncategorized/waste-not/

5. http://www.arpajournal.net/efficiency-as-design/ 